\title{
Collaborative innovation perspective of improving the quality of graduate education
}

\author{
Shuoyi He \\ The graduate school, Tianjin University of finance and economics, Tianjin, 300222, China. \\ showyoeho@163.com
}

Keywords: Graduate education, innovative education, collaborative innovation.

\begin{abstract}
The 21st century is talent competition, cultivate creative talents is to build an innovationoriented country, the important strategy of human resources power. Graduate education undertakes the task of training high-level innovative talents, attaches great importance to the work of graduate student education, improve the quality of graduate education is to carry out the ministry of education of colleges and universities the inherent requirement of "graduate student education innovation plan". Deepen the graduate student education innovation plan is comprehensive and enhance personnel training quality in colleges and universities is an important content, collaborative and center for all kinds of excellent talents with innovation provides a good platform.
\end{abstract}

\section{Introduction}

In 2012, the ministry of education, ministry of finance and start the "innovation ability of institutions of higher learning promotion plan" (hereinafter referred to as "2011 plan"), by introducing a concept of collaborative innovation, further deepen the connotation of postgraduate innovative education theory.Synergy innovation concept is with now advocates the education system reform in our country, closely related to science and technology system reform, is the transformation of higher education thoughts deeper.Collaborative innovation emphasis on talent cultivation, discipline construction, scientific research of the trinity, through the innovation of the system and mechanism innovation elements in fusion.For collaborative innovation, how to make it better with combination of talent training, especially the high level of graduate education, is each college must face an important problem.

\section{Collaborative Innovation and the Connotation of Innovative Personnel training}

\subsection{The Scientific Connotation of Collaborative Innovation}

The Massachusetts institute of technology professor Peter becomes first suggested Collaborative Innovation (Collaborative Innovation) the connotation of the "group of motivated people network to form the collective vision, with the aid of network exchange ideas, information and work conditions, cooperation to achieve common goals".

Essence, collaborative innovation is a kind of management innovation, cooperative innovation main body of the multi-layered, purpose is to better play together all the innovation main body characteristics, through innovation promotes the innovation main body of innovation ability, thus realize the complementary advantages, mutual benefit and win-win results. The innovation main body includes: institutions of higher learning and scientific research institutes (knowledge innovation main body), enterprise technology innovation (subject), the government departments at all levels (policy innovation main body).

\subsection{The Related Explanation of Cultivating Creative Personnel}

Innovative talent is to point to have certain professional knowledge or specialized skills, carry out innovative labor and significant contributions to society.Innovative talents belong to the human resources ability and quality were higher in that part of the laborers.Innovative talents is the creator of the new knowledge, new technology, the inventor, the creator of a new discipline, the trainers, the pioneers of the new market of new products, is the science and technology innovation, knowledge 
innovation and method innovation leader.Can say, innovative talent training research has become one of the main content of higher education research in our country.

To cultivate innovative talents, must have a high quality of higher education, as well as the combination of scientific research, industry and education. At the same time, higher education should focus on cultivating innovative talents in collaborative innovation implementation, and to train innovative talents to promote the collaborative innovation.

\subsection{Collaborative Innovation Revelation for The Innovative Talent Training}

How to better synergy innovation combined with a high-level talents training, is an important topic of higher education research have to think about.In collaborative innovation center as the platform, with a high level of scientific research to support high quality of higher education, through collaborative innovation to promote the improvement of talent training quality.

Collaborative innovation brought some enlightenment to innovative talent training:Ideas, want to work in teaching, student work, security management and service, pay attention to the overall thinking of follow up and work in the whole advancement;System design, colleges and universities should pay attention to the organization function of the play, and to mobilize teachers' leading role and students' main body role;Personnel training mode, to form an synergy between teaching and scientific research and industry innovation mechanism.

Visible, in the innovative talent training needs to consider several collaborative elements including: advanced education idea and advanced education system on the synergy; Teachers' leading role and students' main body role of coordination; Teaching content and teaching method of coordination; The school education and social practice together; Comprehensive development and personal growth together.

\section{The Experience of Cooperative Training Top Creative Talents of Using for Reference}

The mollier act of the United States announced, fully embodies the characteristics of American graduate education service for the society. The graduate education in the United States are leading the development of graduate education around the world.

\subsection{The Main Path of Top Creative Talents Training}

3.1.1Together to build science and technology park and research center, provide practical training platform for top creative talents training.Around the middle of the 20th century, the United States in some universities set up the high and new technology industrial park, such as relying on the Stanford university and the university of California, Berkeley, famous silicon valley science and technology park, relying on the university of north Carolina, duke university and the university of north Carolina triangle park, north Carolina, etc.Big companies such as IBM, Ericsson, dupont in the science and technology park, gives around college students directly involved in the production practice of the platform, has realized the combination of theory and practice, provide important channel for training top creative talents.

America's universities and enterprises to build engineering research center and application development research center, the exchange of personnel to conduct research work on both sides, with the research and development of cross subject and dual tasks of top creative talents training. Research center of the establishment of colleges and universities and industry scientists with different knowledge background and special skills, excellent students with engineer for interdisciplinary research.

3.1.2Collaborative scientific research project, provide project support for top creative talents training.America, the research topic put forward by college and enterprise, to share, research the results generally also can be directly applied in product development.Synergy for the vast majority of scientific research project is about a certain industry general technical problems and the application prospect of the project.Production synergy to undertake research projects widely used have the firstclass research university at the university of California, Berkeley, MIT, Stanford university and so on.

3.1.3.Joint research plan, provide effective carrier for top creative talents training.Research universities in the United States attaches great importance to in the process of top creative talents 
cultivation of students' scientific research ability and practice ability exercise and training, through joint research projects with scientific research institutions, enterprises, provide scholarship support for students, to attract outstanding students to participate in the scientific research work.

3.1.4Companies and foundations provide funding for top creative talents training.American funds of production-study-research cooperative training top creative talents, as is by the national science foundation (NSF) grant funding. Since the $1960 \mathrm{~s}$, many American companies or independent foundations are involved in the university talents training plan, set up a scholarship as a student of the special research fund or fund grants, scholarships, all kinds of subject contests. The companies and foundations in the United States and universities or research institutions to establish long-term cooperative relations, effectively promote a large number of outstanding students to participate in scientific research, cultivate the students' scientific research ability, can also produce a batch of scientific research to solve practical problems.

\subsection{The Synergy of Cultivating Graduate Students Reform Experience}

From 2010 to 2012, the United States has issued "the way forward: the future of American graduate education", "the way forward propulsion," and "from the graduate school to career", the three important report not only analyzes the present situation and problems of the development of postgraduate education in the United States, and determines the basic direction of American graduate education reform.Academia, industry, and is basically in accordance with the "way forward" in politics the identified cooperation framework for the corresponding reform.

Increasingly obvious academic understanding of the importance of graduate education, colleges and universities are also actively reform measures, cultivate and adapt to the market demand of graduate students, focus on training the regional development, nonprofit organizations and government departments need senior talents.

Industry business leaders are also actively support the teaching and scientific research activities.America's biggest companies are hoping to hire to both have received higher education, and quickly adapt to the work after the training of employees, and need to be able to provide the project plan to deal with the business and social problem thinker.

The government related legislation to increase support for graduate education.2011 in the journal of the American competitiveness reauthorization act enacted more than support the terms of the graduate education reform and development.

\section{Explore Collaborative Cultivate Innovative Talents of Graduate Practice in China}

Draw lessons from abroad such as the United States "silicon valley" the successful practices of joint study, since the $1990 \mathrm{~s}$, China began to implement the graduate student's union. Years of practice has proved that China's academia, industry and education are recognized the personnel training mode, and constantly explore suitable for China's national conditions of production, the effective path of training innovative talents.Practice, our country has already formed the introduction of enterprise tutor professor, build the workstation, industry, relying on the major research projects and other production of the postgraduate training mode.

In recent years, our country set up the first batch of 14 collaborative innovation center in cultivation in the process of the formation and development, the reform of talent cultivation has achieved certain results. "Collaborative innovation center in 2014 according to the ministry of education graduate student enrolment plan" (see annex) data, the current collaborative innovation center to recruit a total of $2041 \mathrm{PhD}$ students and 2041 graduate student, the recruitment of students scale in steady growth.

\subsection{Part of the Graduate Education in Collaborative Innovation Center Reform Practice}

4.1.1Beijing university of aeronautics and astronautics led "advanced aeroengine collaborative innovation center" by taking colleges and universities, enterprises double tutorial system, international joint training mechanism, personalized custom training mechanism, small class teaching mode reform measures, such as promoted the school "the three" aircraft engine the effective implementation of the elite talents cultivation model.

4.1.2Led by Harbin institute of technology's "aerospace science and technology of collaborative innovation center" by setting up international post-doctoral positions, to attract first-rate universities 
and academic institutions, a doctoral student, in order to promote the development of high-level research talents.

4.1.3Nanjing university of technology "advanced biological and chemical manufacturing collaborative innovation center" set up "2011" college, college is divided into biological engineering, chemical engineering and technology, materials science and engineering, four optoelectronic information science and engineering major, pass through this Thurber course system, realized the Thurber $(3+2+3)$ even reading training mode, at the same time, college implement small class teaching, the teaching, discussion and experiment, the combination of many forms such as enterprise practice teaching method, part of the course for an English lecture.

4.1.4Sichuan university, led by biological treatment of collaborative innovation center introduced a doctoral student admissions "+ interview application" audit system, flexible educational system, the implementation of joint cultivation between the platform and the platform between the tutor system, elected course mutual recognition, opening laboratory, realize the cross in the true sense of discipline.

4.1.5Led by Tianjin university, Nankai university of "collaborative innovation center in Tianjin chemical engineering" on the graduate admissions to implement dynamic access mechanism, multiple selection, for outstanding students "- - to recognize bo" even read mode of talent training, elective courses encourage, exam achievement eligible, can exempt the course at the postgraduate level.Good students will participate in the center of scientific research work, being part of a team, through lets the student participate in high level scientific research project, the realization of the aim of cultivating high-level innovative talents.

\subsection{Study the Practice Exploration of The Postgraduate in Our City}

In December 2010, Tianjin university of science and technology cooperation with Tianjin SAN wei technology development co., LTD. Set up the "Tianjin university of science and technology institute of mechanical engineering graduate student innovation practice base"; The establishment of practice base is in Tianjin university of science and technology institute of mechanical factors: insist for a long time and a new step.Establish graduate student innovation practice base, is in response to country to develop the master of engineering, improve the master of engineering practice ability, practical ability, is a new exploration.

Founded in June 2008, Tianjin electric power and Tianjin University graduate joint training center.Appointed by the Tianjin university outstanding student with Tianjin electrical technology research institute researchers around the grid development and construction of the key technical problems in technical research.In recent years, the close cooperation between colleges and many achievements have been successful in the actual work of Tianjin grid operation; the joint training graduate student has obtained the remarkable economic and social benefits.

2013 zhuhai vigorously implement the "2011 plan", encourage colleges and universities around the country to the city and regional economic and social development of major requirements, construction of a number of field synergy innovation center, cultivate a further five "high starting point, high standard, has a characteristic" collaborative innovation center, the level of improving talent cultivation, discipline construction, scientific research in colleges and universities in the city of the trinity of collaborative innovation ability.

The concept of collaborative innovation constantly push to further promote innovation ability of colleges and universities in the city.Tianjin university this year's focus is on the scientific research management system reform and innovation, the real school culture of innovation organization together, in the academic development, as well as the society, industry, service industry, centering on the goal, break down barriers of hamper innovation system mechanism, and realize the innovation of the management mode.

\subsection{Collaborative Innovation Center in China Are Faced with the Problem}

"2011" collaborative innovation center in research, mentors, funds and other advantages, create a unique platform for talents cultivation.But, on the part of collaborative innovation center after the research found that the center of talent cultivation in the graduate student is still facing some problems in aspects of mechanism system: 
4.3.1The allocation of resources.Collaborative innovation center has excellent innovation platform, strong faculty and enough practice internship base, graduate students need to meet the needs of individual development, the reasonable configuration and make full use of various resources, in order to realize the maximization of resource utilization efficiency and the optimization of the students.

4.3.2Student management.Collaborative innovation center in the graduate student talent training will be involved in the daily teaching management, student status management degree and internship practice management, therefore, implements standardization management to the student center in the cultivation of talents is an urgent need to solve an important problem.

4.3.3The training process.Collaborative innovation center to formulate specific graduate student talent training plan, set up and optimize the curriculum teaching, design the content of the funding for students, setting up a scientific evaluation system for the quality of graduate students.

\section{References}

[1]. Du Yubo, higher education to more adapt to the needs of economic and social development, "China Education News" July 24, 2014 third edition

[2]. Zhang Xinchao, Zhong Shanshan. "Production and research" joint training compound graduate model [J]. Higher Education Research, 2009 (1): 57-60.

[3]. Gao Xingwu, Hu Yong. The Status Quo, Problems and Countermeasures of Jointly Cultivating Postgraduates in Beijing Municipality - Based on the Analysis of Questionnaire [J]. China Higher Education Research, 2010 (11): 42-46.

[4]. Chen Wen, Yu Yong. Research on the Mode of Cultivating Graduate Students in Production and Research Cooperation - Taking Guangxi Normal University College of Life Science as an Example [J]. Degree and Graduate Education, 2012 (12): 41-45.

[5]. Li Huimin, Zhang Wang. Production and research cooperation to promote postgraduate training [J]. Chinese University Science and Technology, 2013 (7): 42-43.

[6]. Chen Wen, Peng Wen, Peng Yong.Study on the Development of Graduate Education Cooperation Mode - Based on the Stakeholder Theory [J]. Journal of Guangxi Normal University, 2013 (2): 144-148.

[7]. Wu Fei, Zhang Hong. Production and research cooperation and postgraduate innovation ability training [J]. China Higher Education Technology, 2011 (7): 34-35. 